\title{
COPPER ANCHORED TO AMINO-GROUP FUNCTIONALIZED SILICA GEL AS WOOD PRESERVATIVE AGAINST BROWN-ROT DECAY*
}

\author{
S. Palanti ${ }^{1}$, E. Feci ${ }^{1}$, G. Predieri ${ }^{2}$, F. Vignali ${ }^{2}$
}

\begin{abstract}
The aim of this research was to realize new potential wood preservatives against fungal decay, with low environmental impact and well fixed into the wood.

Pinus sylvestris L. wood samples were impregnated by silica xerogels functionalized with amino groups able to link copper through coordinative interactions. In this study tetraethoxysilane (TEOS) and 3-aminopropyltriethoxysilane (APTES), in different ratios, and linked with copper or not, were utilized to impregnate wood samples, in order to evaluate the factors responsible for the efficacy against the brown rot Coniophora puteana. The fixation to the wood was evaluated through the leaching procedure (EN 84) and the variation on the effectiveness against this fungus.
\end{abstract}

The sol-gel processes TEOS/APTES, ratio 1:1, with or without copper, leached or not leached, showed a good effectiveness against fungus C. puteana.

Keywords : alkoxysilanes, sol-gel processes, Coniophora puteana, wood decay.

\section{INTRODUCTION}

Alkoxysilanes are molecules with formula $\mathrm{R}_{\mathrm{n}} \mathrm{Si}\left(\mathrm{OR}^{\prime}\right)_{(4-\mathrm{n})}$ where $\mathrm{n}=0,1,2$ or 3 that might to be utilized to modify the surface of numerous substrates. Anchoring of metal cations onto a functionalized xerogel silica matrix is a well-established procedure developed about twenty years ago and utilized mainly to produce grafted metal catalysts (Khatib and Parish 1989, Ferrari et al. 1992, Klonkowsky et al. 1999). Wood modified by alkoxysilanes shows lowering in humidity absorption (Brebner and Scneider 1985), increasing in dimensional stabilization (Saka et al. 1992), resistance to the fire (Saka and Ueno 1997), enhancing of its resistance against soil micro-organisms and termites (Donath et al. 2004, Feci et al. 2009). Moreover, a recent review describes how the properties of wood might be improved by application of silica and other inorganic nanosols (Malthig et al. 2008).

The present research arises from the demand to develop wood preservatives with a broad spectrum of action, a low environmental impact and a good fixation into the wood.

For these purposes Pinus sylvestris L. wood was impregnated by silica xerogels, where tetraethoxysilane (TEOS) and 3-aminopropyltriethoxysilane (APTES) were the main components in different ratio between them and linked with copper or not, in order to evaluate which components principally determine the efficacy against the brown $\operatorname{rot} C$. puteana.

The fungicidal properties of $\mathrm{Cu}^{2+}$ are due to the denaturation of proteins and enzymes, owing to the $\mathrm{Cu}^{2+}$ affinity for thiol groups in the fungal cell, and to the inhibition of respiration, owing to $\mathrm{Cu}^{2+}$ interference with the activity of conversion of pyruvate to acetyl coenzyme A (Eaton and Hale 1993). Copper biocide properties are expected to be not significantly reduced by the labile coordinative linkage with the siloxane amine groups, as copper ions maintain their mobility.

\footnotetext{
*This paper was originally presented at the 2010 EC-IAWS/ESTB7 meeting, Rabat-Morocco, March 2010, and has been updated.

${ }^{1}$ C.N.R. - IVALSA, Istituto per la Valorizzazione del Legno e delle Specie Arboree Via Madonna del Piano, 10 I-50019 Sesto Fiorentino, Firenze

${ }^{2}$ Dipartimento di Chimica G.I.A.F., Universit_di Parma Viale G.P. Usberti 17/A I-43100 Parma

Corresponding author: palanti@ivalsa.cnr.it

Received: 07.06 2010. Accepted: 03.10. 2010.
} 
Transition metal complexes can exchange metal ions with other competitor ligands (e.g. thiol groups or proteins) in amounts which depend on the formation constants of the relevant complexes.

The fixation to the wood was evaluated through the leaching procedure (EN 84) and the variation that this ageing procedure determined on the effectiveness against fungal decay.

\section{Wood samples}

\section{MATERIAL AND METHODS}

Wood blocks of Pinus sylvestris L. sapwood, $30 \times 10 \times 5 \mathrm{~mm}^{3}$ were conditioned to constant mass at $20^{\circ} \mathrm{C}$ and $65 \%$ relative humidity $(\mathrm{RH})$ before being subjected to the impregnation processes. The respective oven dry weight of the wood blocks were previously determined.

\section{Impregnation of wood with sol-gel processes}

Wood blocks were treated by impregnation under vacuum (55 mbar) at R.T., with different sol-gel mixtures described below:

1. TEOS/ APTES 1:1 (v/v) $+\mathrm{Cu}(\mathrm{Cu} /$ APTES molar ratio 1:5). Tetraethoxysilane (TEOS, $10 \mathrm{ml}$, $44.8 \mathrm{mmol}$ ), 3-aminopropyltriethoxysilane (APTES, 10ml, $42.8 \mathrm{mmol}$ ), copper (II) chloride $(8.53 \mathrm{mmol})$ and ethanol $(20 \mathrm{ml})$.

2. TEOS/ APTES 1:1 (v/v). Tetraethoxysilane (TEOS, 10ml, 44.8 mmol), 3-aminopropyltriethoxysilane (APTES, $10 \mathrm{ml}, 42.8 \mathrm{mmol}$ ), and ethanol (20 ml).

3. TEOS/ APTES 10:1 (v/v) $+\mathrm{Cu}(\mathrm{Cu} /$ APTES molar ratio $1: 5)$. Tetraethoxysilane (TEOS, $19.1 \mathrm{ml}, 85.5 \mathrm{mmol}$ ), 3-aminopropyltriethoxysilane (APTES, $1.9 \mathrm{ml}, 8.1 \mathrm{mmol}$ ), copper (II) chloride $(1.7 \mathrm{mmol})$ and ethanol $(21 \mathrm{ml})$.

4. TEOS/ APTES 10:1 (v/v). Tetraethoxysilane (TEOS, 19.1ml, 85.5 mmol), 3-aminopropyltriethoxysilane (APTES, $1.9 \mathrm{ml}, 8.1 \mathrm{mmol})$, and ethanol $(21 \mathrm{ml})$.

The blocks, after a vacuum exposure of $45 \mathrm{~min}$, were dipped in the sol-gel mixture under vacuum. Subsequently the mixture was gently stirred under nitrogen for $30 \mathrm{~min}$ at $1 \mathrm{~atm}$. Then the samples were recovered and dried at room temperature and atmospheric pressure for $24 \mathrm{~h}$. Furthermore the respective oven dried weights were determined.

Characterization of the impregnation processes was performed through the determination of weight percent gain (WPG), calculated as follows:

$$
W P G=\frac{M_{t}-M_{0}}{M_{0}} \times 100
$$

where $\mathrm{M}_{\mathrm{o}}$ and $\mathrm{M}_{\mathrm{t}}$ are the oven dried weights of untreated and sol-gel treated wood specimens, respectively.

\section{Leaching}

One set of impregnated wood specimens for each of the four sol-gel treatments, was subjected to the leaching procedure according to EN 84 (1997). Wood specimens were placed in a glass beaker filled with deionised water conforming to EN ISO 3696 (1996). Wood specimens were prevented from floating by the use of weights. The beaker was put in a desiccator and vacuum was applied corresponding to a residual pressure of $4 \mathrm{kPa}$. Vacuum was maintained for 20 minutes, and then released to return to normal pressure. Wood specimens were maintained in water (ratio of water to wood 5:1) for 14 days with 9 water changes, and then conditioned to constant mass. 
Filtered solutions $(100 \mathrm{ml})$ were subjected to elemental ICP analysis for the determination of $\mathrm{Si}$ and $\mathrm{Cu}$ by using a Jobin Yvon Ultima 2 ICP equipment.

Total copper and silicon content inside the wood specimens were determined after extraction with sulphuric acid. Concentrations were expressed in $\mathrm{kg} / \mathrm{m}^{3}$.

\section{Characterization of sol-gel process}

\section{FT-IR spectroscopy}

FT-IR spectroscopy was performed on untreated pine samples, on samples treated with sol-gel TEOS/ APTES 1:1 and on sol-gel TEOS/APTES 1:1 obtained in a Petri dish without wood. The spectrometer used was a Brucker FTIR (Alpha) with the following setting: 60 scans per sample, spectral resolution $4 \mathrm{~cm}^{-1}$, wave number range: $4000-400 \mathrm{~cm}^{-1}$, using a diamond single reflection attenuated total reflectance (ATR).

\section{SEM EDS analyses}

Specimens treated with sol-gel processes TEOS/APTES 1:1 and $\mathrm{CuCl}_{2}$, were cut along the cross section to obtain two parts of the same length.

The cut was performed using a $\mathrm{CO}_{2}$ Laser (power max $2 \mathrm{~kW}$ El. En), with emission wave length $10.6 \mu \mathrm{m}$ and power $500 \mathrm{~W}$, laser beam diameter width $3 \mathrm{~mm}$, air flow pressure 0.5 bar. During cutting the sample was positioned at a distance of $10 \mathrm{~mm}$ from the lens focus of the laser source to obtain two equal cross sections.

AJeol 6400 Scanning Electron Microscope equipped with an Energy Dispersive Microanalysis Oxford INCA was utilized. Operating conditions were $15 \mathrm{kV}$ and $1.2 \mathrm{nA}$, electron beam about $1 \mu \mathrm{m}$ in diameter and $100 \mathrm{~s}$ counting times. Errors were $\pm 2-5 \%$ for major elements and $\pm 5-10 \%$ for minor components.

The evaluation of the penetration into the wood was made performing nine X-Rays microanalysis in areas at different depth into the cross section of a specimen. The atomic ratios were determined.

Silicon and copper X-ray maps were performed all over the cross section.

\section{Accelerated fungal decay test}

Sets of samples representative of each sol-gel treatment, leached or not leached, were exposed to the fungus Coniophora puteana (Schumacher ex Fries) Karsten strain BAM Ebw. 15.

Each set of treated samples was placed in a Kolle flask together with two untreated reference samples of sapwood of Pinus sylvestris L.. Each flask contained the brown rot fungus grown on $20 \mathrm{ml}$ of $4 \%$ malt and $2.5 \%$ agar medium. The wood blocks were incubated with the fungus for eight weeks at $22{ }^{\circ} \mathrm{C}$ and $75 \% \mathrm{RH}$. The resistance against $C$. puteana was evaluated through the measurement of the mass loss of wood, which was calculated for each individual block as the difference between the dry mass before the impregnation process and after the fungal exposure, corrected by the WPG due to the impregnated treatment.

\section{RESULTS AND DISCUSSION}

Impregnation of wood with sol-gel processes

As shown in Table 1, the WPG data of different sol-gel treatments do not appear influenced by the concentration of copper chloride and APTES, but appear strongly dependent on the concentration 
of TEOS, which was in all the four mixtures, the major component. A great variability is observed in all four processes. The number of ring for cross section seemed also to influence the sol-gel treatment:-an increase of WPG was observed in correspondence to the lowering of number of rings. An explanation could be due to the fact that the early wood is more permeable than late wood to the silicates.

The increasing of density due to the sol-gel treatments is expressed from the same percent value of WPG considering that each wood block had the same nominal volume $\left(1.510^{-6} \mathrm{~m}^{3}\right)$.

Table 1. Averages and standard deviation dry masses before and after sol-gel processes and mean weight percent gain.

\begin{tabular}{|l|c|c|c|}
\hline \multicolumn{1}{|c|}{ Sol-gel treatment } & $\begin{array}{c}\text { Mean Initial dry } \\
\text { mass and sd (g) }\end{array}$ & $\begin{array}{c}\text { Mean dry mass } \\
\text { and sd after sol-gel } \\
\text { process (g) }\end{array}$ & WPG (\%) \\
\hline $\begin{array}{l}\text { TEOS/ APTES 1:1, } \mathrm{Cu} \\
(\mathrm{n}=7)\end{array}$ & $0.674 \pm 0.039$ & $0.856 \pm 0.056$ & $27.06 \pm 5.39$ \\
\hline TEOS/ APTES 1:1 $(\mathrm{n}=8)$ & $0.726 \pm 0.081$ & $0.889 \pm 0.080$ & $22.78 \pm 6.33$ \\
\hline $\begin{array}{l}\text { TEOS/ APTES 10:1. Cu } \\
(\mathrm{n}=7)\end{array}$ & $0.633 \pm 0.047$ & $0.762 \pm 0.051$ & $20.50 \pm 3.54$ \\
\hline TEOS/ APTES 10:1 $(\mathrm{n}=6)$ & $0.688 \pm 0.104$ & $0.861 \pm 0.089$ & $26.09 \pm 9.69$ \\
\hline
\end{tabular}

\section{Characterization of sol-gel process}

Figure 1 shows the IR spectra of untreated pine wood, of sol-gel treated pine wood and of a pure sol-gel material (xerogel) obtained by TEOS/APTES without wood.

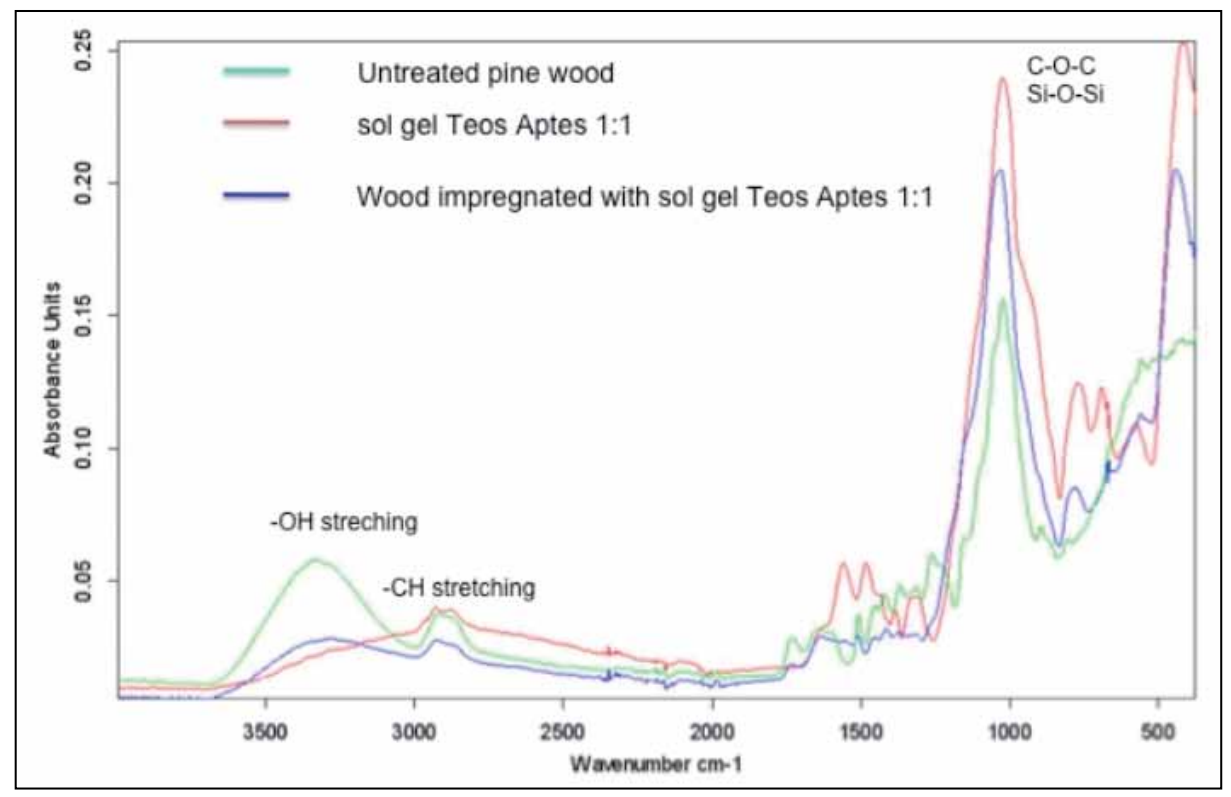

Figure 1. FT - IR spectrum of untreated pine, TEOS/APTES 1:1 xerogel and wood impregnated with sol-gel process TEOS/APTES 1:1

Spectra of untreated pine wood. The attributions of the peaks in the finger-print region between 1800 and $600 \mathrm{~cm}^{-1}$ were assigned to the wood components (Pandey and Pitman 2003): 1734-1738 $\mathrm{cm}^{-1}$ $\mathrm{C}=\mathrm{O}$ in xylans (hemicelluloses), $1650 \mathrm{~cm}^{-1}$ absorbed $\mathrm{O}-\mathrm{H}, 1596 \mathrm{~cm}^{-1}$ conjugated $\mathrm{C}-\mathrm{O}$ and $1023 \mathrm{~cm}^{-1}$ 
C-O-C vibrations; in the region of $1462-1158 \mathrm{~cm}^{-1}$ and peak at $898 \mathrm{~cm}^{-1}$ there were the typical wavenumbers of wood components hemicelluloses and lignin. The peaks at $3329 \mathrm{~cm}^{-1}$ and at 2920 $\mathrm{cm}^{-1}$ were attributed respectively to $-\mathrm{OH}$ stretching and $\mathrm{C}-\mathrm{H}$ stretching.

Spectra of sol-gel performed with TEOS and APTES 1:1 into the wood. In this spectra it is interesting to observe that peaks at $3329 \mathrm{~cm}^{-1}$ and also those between 1800 and $1100 \mathrm{~cm}^{-1}$, belonging to wood components, are weaker with respect to the untreated wood. This fact could be due to the xerogel formation that hid the functional group of wood. The peak around $1000 \mathrm{~cm}^{-1}$ appears increased due to the absorbance of Si-O-Si linkage. Also bands at 780 and $430 \mathrm{~cm}-1$ appear due to the xerogel.

The FT-IR spectrum of TEOS and APTES 1:1 xerogel without wood is characterized by the typical bands of the hybrid TEOS/APTES sol-gel material;-around $1500 \mathrm{~cm}^{-1} \mathrm{NH}_{2}$ bending, 930 (shoulder), 760, 668 and $430 \mathrm{~cm}^{-1} \mathrm{Si}-\mathrm{O}-\mathrm{Si}$ skeleton.

\section{SEM EDS analyses}

The effectiveness of wood impregnation by the functionalized silica gel was evaluated by SEM investigations. In particular silicon and copper were determined by X-ray microanalysis carried out in eight different areas at different depth into the cross sections of a representative specimens treated with TEOS/APTES 1:1 and $\mathrm{CuCl}_{2}$. Figure 2 shows the areas, from surface to bulk, where the spectra were performed across the section. The $\mathrm{Si} / \mathrm{Cu}$ atomic ratio remains almost constant (about 10:1), suggesting that silicon and copper penetrated homogeneously into the wood during the sol-gel process.

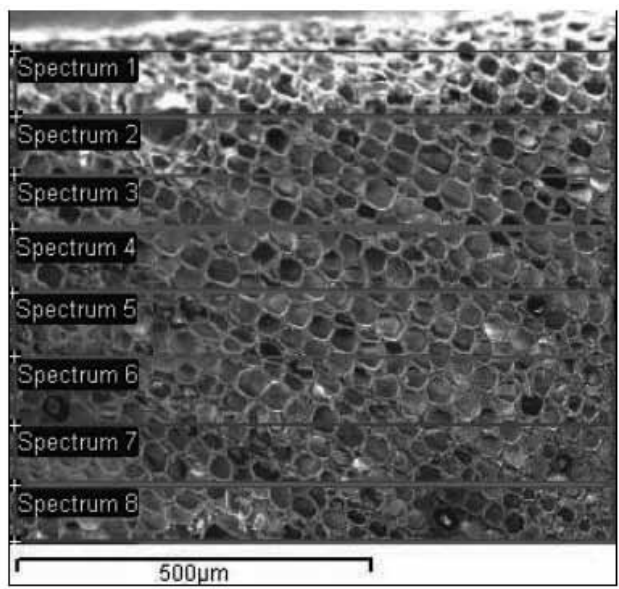

Figure 2. Different areas (1-8 from surface to bulk) where X-rays microanalysis were performed.

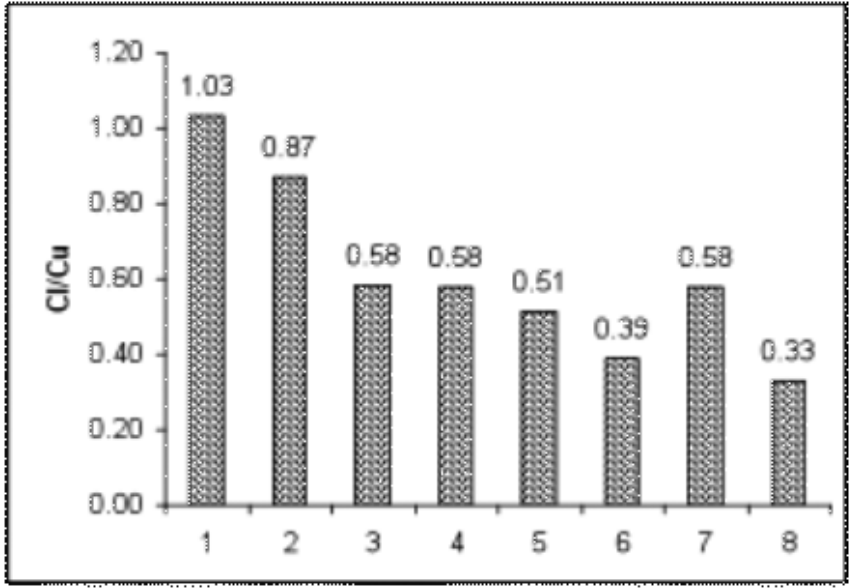

Figure 3. $\mathrm{Cl} / \mathrm{Cu}$ atomic ratios at different distance from the sample surface. 
$\mathrm{The} \mathrm{Cl} / \mathrm{Cu}$ atomic ratio as a function of penetration is reported in figure 3. It progressively decreases suggesting that copper cations interact more and more with the silanolate groups as the sol penetrates into the wood.

Moreover, observation of the silicon and copper maps performed with SEM shows that the two elements are distributed all over the wood cell wall (Figures 4, 5, 6).

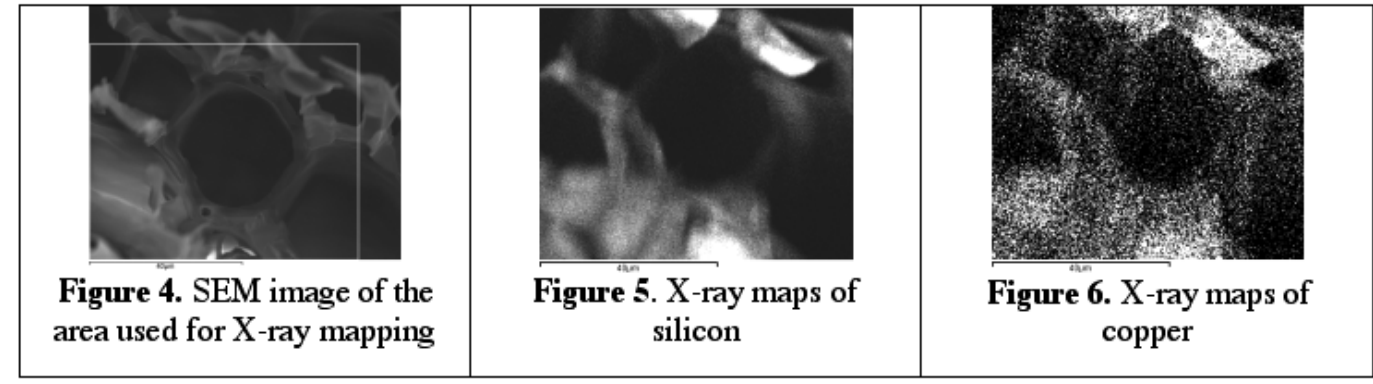

In the case of sample containing TEOS/APTES in 10:1 ratio and $\mathrm{CuCl}_{2}$ in $\mathrm{APTES} / \mathrm{Cu}$ 5:1 ratio, penetration of copper is much less pronounced, the metal cation being mainly anchored onto the wood surface probably owing to the presence of relatively low concentration of ammine function in the siloxane network. This causes fixation of copper by silanolate function present in high concentration even on the surface.

\section{Accelerated fungal decay test}

The results expressed in terms of average mass loss and standard deviation are shown in table 3. For each treatment, the results are expressed respectively for samples leached or not leached. These are only preliminary results because the number of replicates is limited, but it is possible to observe a significant protective activity of TEOS and APTES components, with copper and also without copper when their ratio is $1: 1$. At this relative concentration the leaching treatment did not influence their fungicidal activity.

When the ratio between TEOS and APTES is 10:1 the treatment appears ineffective in absence of copper. The presence of copper in 5:1 APTES/Cu ratio seems to provide biocide efficacy to the treatment, as the mass loss results rather scarce. However, the leached samples do not exhibit the same resistance. This is probably due to the removal of copper from the surface where the metal cation is present in higher concentration than in the bulk (as stated above), resulting in the fall of a sort of barrier effect.

From the ICP analyses comes out that the $\mathrm{Cu}$ loss due to leaching is $12 \%$ of the total $\mathrm{Cu}$ content of the samples $\left(0.6 \mathrm{~kg} / \mathrm{m}^{3}\right)$ whereas silicon loss is $0.7 \%$ (total content $37.8 \mathrm{~kg} / \mathrm{m}^{3}$ ). On the other hand, in the case of TEOS/APTES 1:1 samples with $\mathrm{CuCl}_{2}$ (APTES/Cu 5:1), the $\mathrm{Cu}$ loss is $0.5 \%$ (total copper content $5.4 \mathrm{~kg} / \mathrm{m}^{3}$ ). 
Table 2 .Average mass loss (ML) and standard deviation (sd) of wood samples treated with the different sol-gel processes, leached (Y) or not leached $(\mathrm{N})$

\begin{tabular}{|l|c|c|c|c|}
\hline \multicolumn{1}{|c|}{ Sol-gel process } & $\begin{array}{c}\text { Number } \\
\text { of } \\
\text { samples }\end{array}$ & $\begin{array}{c}\text { Leaching } \\
\text { (Y/N) }\end{array}$ & ML (\%) & sd \\
\hline $\begin{array}{l}\text { TEOS/APTES 1:1, } \\
\mathrm{CuCl}_{2}\end{array}$ & 4 & $\mathrm{Y}$ & -1.5 & 0.6 \\
\hline $\begin{array}{l}\text { TEOS/APTES 1:1. } \\
\mathrm{CuCl}_{2}\end{array}$ & 4 & $\mathrm{~N}$ & 1.1 & 0.27 \\
\hline TEOS/APTES 1:1 & 4 & $\mathrm{Y}$ & -3.93 & 0.46 \\
\hline TEOS/APTES 1:1 & 4 & $\mathrm{~N}$ & 0.4 & 1.1 \\
\hline $\begin{array}{l}\text { TEOS/APTES 10:1. } \\
\text { CuCl } 2\end{array}$ & 4 & $\mathrm{Y}$ & 23.5 & 2.57 \\
\hline $\begin{array}{l}\text { TEOS/APTES 10:1. } \\
\text { CuCl }\end{array}$ & 3 & $\mathrm{~N}$ & 0.26 & 0.08 \\
\hline TEOS/APTES 10:1 & 3 & $\mathrm{Y}$ & 28.6 & 23.8 \\
\hline TEOS/APTES 10:1. & 4 & $\mathrm{~N}$ & 21.28 & 11.1 \\
\hline
\end{tabular}

\section{CONCLUSION}

It is important to remark that our preliminary results were obtained with a limited number of replicates and with accelerated procedure against fungal decay.

This study demonstrates that amino silicates APTES/TEOS in ratio 1:1, with or without copper, and even after leaching, show an efficacy against $C$. puteana. Data obtained from accelerated test against this fungus have to be confirmed by supplementary fungal test with other brown rot and also white rot fungi.

\section{REFERENCES}

Brebner, K.I.; Schneider, M.H. 1985. Wood-polymer combinations: Bonding of alkoxysilanes coupling agents to wood. Wood Sci. Technol. 19: 75-91.

Donath, S.; Militz, H.; Mai, C. 2004. Wood modification with alkoxysilanes. Wood Sci. Technol . 38: $555-566$

Eaton, R. A.; Hale, M.D.C. 1993. Wood: deacy, pests, and protection. Chapman \& Hall, London.

European Committee for Standardization EN 84. 1997. Wood preservatives - Accelerated ageing of treated wood prior to biological testing. Leaching procedure.

European Committee for Standardization EN ISO 3696. 1996. Water for analitycal laboratory use. Specification and test methods.

Feci, E.; Nunes, L.; Palanti, S.; Duarte, S.; Predieri, G.; Vignali, F. 2009. Effectiveness of sol-gel treatments coupled with copper and boron against subterranean termites. IRG/WP 0930493. 
Ferrari, C.; Predieri, G.; Tiripicchio, A.; Costa, M. 1992. Anchoring metal species on a thioureafunctionalized silica xerogel. In situ production of colloidal palladium particles. Chem. Mater 4: 243-245

Khatib, I. S.; Parish, R.V. 1989. Insoluble ligands and their applications. I. A comparison of silicaimmobilized ligands and functionalized polysiloxanes. J Organomet Chem 369: 9-16

Klonkowsky, A.M.; Grobelna, B.; Widernik, T.; Jankowska-Frydel, A.; Mozgawa, W. 1999. The coordination state anchored and grafted onto the surface of organically modified silicates. Langmuir 15: 5814-5819

Mahltig, B.; Swaboda, C.; Roessler, A.; Böttcher, H. 2008. Functionalising wood by nanosol application. J Mater Chem 18: 3180-3192

Pandey, K.K.; Pitman, A.J. 2003. FTIR studies of the changes in wood chemistry following decay by brown-rot and white-rot fungi. International Biodeterioration and Biodegradation 52:151-160.

Saka, S. ; Sasaki, M.; Tanahashi, M. 1992. Wood-inorganic composites prepared by sol-gel processing. Wood-inorganic composites with porous structure. Mokuzai Gakkaishi 38: 1043-1049.

Saka, S.; Ueno, T. 1997. Several $\mathrm{SiO}_{2}$ wood-inorganic composites and their fire-resisting properties. Wood Sci. Technol. 31: 457-466 